\title{
Avaliação da presença de Staphylococaus aureus nos leitos do Centro de Terapia Intensiva do Hospital Escola da Faculdade de Medicina do Triângulo Mineiro, em relação à posição no colchão antes e após a limpeza
}

\author{
Evaluation of presence of Staphdococus aureus on the beds of Hospital Escola's \\ Intensive Care Unit, concerning the position on \\ the mattress, before and after cleaning
}

\author{
Guilhermo Justino Mundim ${ }^{1}$, Roberto Alexandre Dezena', Ana Carolina Santana de Oliveira', \\ Paulo Roberto da Silva ${ }^{1}$, Marilda Cardoso², Gilberto de Araújo Pereira², \\ César Augusto de Morais ${ }^{1}$ e Ana Paula Sarreta Terra ${ }^{1}$
}

\begin{abstract}
Resumo Através de meios de cultura, foi pesquisada a posição de colônias de Staphylococcus aureus em colchões, visando avaliar a eficácia do procedimento de limpeza e desinfecção dos leitos do Hospital Escola da Faculdade de Medicina do Triângulo Mineiro (Uberaba). Foram analisadas amostras de 50 colchões no período de 22 de outubro de 2000 a 16 de janeiro de 2001. As amostras foram coletadas e semeadas, pela técnica de esgotamento, em dois meios de cultivo (ágar sangue e manitol) com posterior realização de provas de catalase e coagulase. Na análise estatística, foram utilizados os testes não paramétricos MannWhitney, Kruswkal- Wallis e Wilcoxon Matched Pairs Test com nível de significância p <0,05. Foram utilizadas 600 placas de meio de cultivo. Houve crescimento em $94(15,6 \%)$, sendo $82(87,2 \%)$ antes e 12 (12,8\%) após a limpeza e desinfecção. Em relação à posição no leito, as amostras semeadas no meio de cultivo com manitol mostraram que não houve redução significativa na posição inferior do leito $(p>0,05)$. Os resultados apontam e alertam para falhas no procedimento de limpeza e desinfecção dos leitos hospitalares por nós estudados.
\end{abstract}

Palavras-chaves: Staphylococcus aureus. Centro de Terapia Intensiva. Infecção hospitalar. Limpeza. Desinfecção.

Abstract By means of culture medium, it was researched the position of the colony of Staphylococcus aureus on the mattress, to evaluate the efficciuoness of the methods of cleaning and disinfection of the river bed in the Faculdade de Medicina do Triângulo Mineiro's School Hospital (Uberaba). It were evaluated fifty mattresses on the period of October 22th (2000) to January 16 $6^{\text {th }}$ (2001). The samples were collected and grown, the exhaustion techinique draining, on two different nutrient bases (blood agar and mannitol salt agar) followed by catalase and coagulase tests. For the statistical analysis, were used non-parametrics tests Mann-Whitney, Kruskal-Wallis, Wilcoxon Matched Pairs Test with significance level $p<0,05$ were used. Six hundred dishes of culture medium have been used. There was growing in $94(15,6 \%)$, being $82(87,2 \%)$ before and $12(12,8 \%)$ after cleaning and disinfection. Concerning the position on the bed, the samples obtained from mannitol salt agar medium showed significant retention on the lower position of bed. The results alert to flaws in the procedure for cleaning and disinfection from the mattresses studied by us.

Key-words: Staphylococcus aureus. Intensive Care Unit. Hospital's infection. Cleaning. Disinfection.

\footnotetext{
1.Disciplina de Microbiologia do Departamento de Ciências Biológicas da Faculdade de Medicina do Triângulo Mineiro. 2.Centro de Graduação em Enfermagem da Faculdade de Medicina do Triângulo Mineiro, Uberaba, MG.

Endereço para correspondência: Dra. Ana Paula Sarreta Terra. Disciplina de Microbiologia/DCB /FMTM. Praça Manoel Terra s/n, 38015-050 Uberaba, MG, Brasil.

Tel: 34 3318-5480; Fax: 34 3318-5462

e-mail: csarreta@terra.com.br

Recebido para publicação em 8/4/2002

Aceito em 10/11/2003
} 
As infecções hospitalares representam um grave problema médico-social e o seu melhor conhecimento, prevenção e controle constituem um desafio a ser enfrentado. Entre os microrganismos associados à etiologia dessas infecções, o Staphylococcus aureus permanece como importante patógeno, sendo responsável por mais de $30 \%$ dos casos de infecções hospitalares ${ }^{2}$. Nos hospitais, os reservatórios são representados por pacientes colonizados, funcionários e pelo próprio ambiente $^{5}$.

Vários fatores relativos a cada elemento da tríade ecológica fundamental (hospedeiro-agente-ambiente) contribuem para a prevalência e a difícil controle destes tipos de infecção ${ }^{7}$. Em relação ao hospedeiro, verificase a existência cada vez maior do número de doentes com defesas diminuídas, seja devido à idade avançada, seja devido as múltiplas doenças subjacentes ou terapêuticas depressoras do sistema imune. Como fatores contribuintes, salienta-se o uso crescente de procedimentos invasivos, tais como catéteres venosos, centrais e arteriais, diálise, ventilação mecânica e intervenções cirúrgicas em doentes, que há alguns anos não apresentavam condições para tal ${ }^{3}$. O principal reservatório de Staphylococcus aureus é o homem, sendo comum a infecção cruzada entre os seres humanos, ocorrendo tanto por via aérea, como precedendo resultar do contato direto com pessoas e objetos inanimados ${ }^{1}$. Além disso, segundo Steere ${ }^{9}$, cerca de $60 \%$ dos adultos são portadores intermitentes, permanecendo obscuros os fatores que controlam a dinâmica da condição de portador. Sua resistência a antimicrobianos é um grave problema, alvo de grande preocupação, tendo este se tornado uma importante causa de infecções piogênicas ${ }^{6}{ }^{8}$.

O único Staphylococcus que produz coagulase é o aureus. Entretanto, a produção de coagulase e beta hemólise são duas características que associam os estafilococos à virulência, embora a primeira pareça ser mais confiável. A capacidade da maioria das cepas de $S$. aureus de fermentar o manitol é uma característica utilizada por muitos microbiologistas para sua identificação ${ }^{91011}$. Com relação ao ambiente, salientamse fatores institucionais, tais como o relacionamento doente/pessoal de saúde e unidades de cuidados intensivos médicos e cirúrgicos ${ }^{4}$.

Este trabalho avalia a presença e a posição das colônias de $S$. aureus nos leitos do Centro de Terapia Intensiva (CTI) do Hospital Escola (HE) da Faculdade de Medicina do Triângulo Mineiro (FMTM), antes e após a limpeza.

\section{MATERIAL E MÉTODOS}

Foram avaliadas amostras obtidas de 50 colchões do CTI/HE/FMTM, coletadas no período de $22 / 10 / 2000$ a 16/01/2001, a partir de swabs estéreis umidecidos em soro fisiológico estéril, por rolamento nas três áreas (superior, média e inferior) da superfície em contato com o paciente. As amostras foram colocadas em caldo Brain Heart Infusion (BHI) e semeadas em meio de cultivo ágar sangue e manitol.

Estas amostras foram coletadas imediatamente após a desocupação dos leitos, sendo obtidas uma de cada área. Após desinfecção dos leitos usando água, sabão e álcool $70 \%$, foi realizada uma nova coleta. Depois de coletadas, as amostras foram incubadas em estufa por 30 minutos em caldo $\mathrm{BHI}$ e, em seguida, semeadas pela técnica de esgotamento em meio de cultivo ágar sangue e manitol e incubadas a $37^{\circ} \mathrm{C}$ durante 24 a 48 horas.

As amostras que revelaram a presença de colônias de cocos com características sugestivas de $S$. aureus foram reisoladas em novo ágar $\mathrm{BHI}$ e, após 24 horas a $37^{\circ} \mathrm{C}$, submetidas à prova de catalase e coagulase. Todas as colônias que apresentaram características compatíveis com Staphylococcus aureus foram submetidas à confirmação microscópica após coloração pelo método de Gram.

A caracterização das amostras de Staphylococcus aureus foi realizada pela evidenciação de provas de coagulase positiva, catalase e fermentação em manitol. As amostras cujas provas de coagulase em tubo mostraram-se duvidosas foram submetidas à prova de coagulase, em lâminas com hemácias de carneiro, previamente sensibilizada com hemolisina e fibrinogênio (Staphy-Test, Probac do Brasil).

$\mathrm{Na}$ análise estatística, foram utilizados os testes não paramétricos Mann-Whitney, Kruskal-Wallis e Wilcoxon Matched Pairs Test com nível de significância $p<0,05$.

\section{RESULTADOS}

Observou-se que dos 50 colchões avaliados, com 600 placas de cultivo, houve crescimento de $S$. aureus em $94(15,6 \%)$, sendo $82(87,2 \%)$ antes e $12(12,8 \%)$ depois da limpeza e desinfecção.

De acordo com o teste não paramétrico de MannWhitney, tanto antes quanto após limpeza e desinfecção do leito, o número de $S$. aureus era sempre menor que de outros cocos Gram positivos $(p<0,05)$.
Com o teste Kruskal-Wallis, pode-se notar que tanto o número de colônias quanto as provas de coagulase positivas, não apresentaram diferença significativa entre as regiões superior, média e inferior do colchão quando analisadas, separadamente, antes e após a limpeza e desinfecção.

Em meio ágar sangue, de acordo com Wilcoxon Matched Pairs Test, houve redução significativa no número de colônias de $S$. aureus em todas as posições 
do colchão: sendo a superior $(p=0,033)$; a média $(p=0,009)$; e a inferior $(p=0,030)$ (Figura 1). Confirmando esse padrão, as provas de coagulase das amostras obtidas de meio ágar sangue também mostraram redução significativa em todas as posições do colchão, sendo a superior $(p=0,006)$; a média $(p=0,003)$ e a inferior $(p=0,026)$.

Já em meio manitol, de acordo com Wilcoxon Matched Pairs Test, houve redução significativa no número de colônias de $S$. aureus nas posições superior $(p=0,007)$ e média $(p=0,012)$ dos colchões, após a limpeza e desinfecção. Na posição inferior, não houve redução significativa no número de colônias, sendo $(p=0,082)$ (Figura 2). O número de provas de coagulase, de amostras obtidas em meio ágar manitol, também apresentou padrão semelhante, tendo redução significativa nas posições superior $(p=0,005)$ e média $(p=0,019)$ não houve redução significativa na posição inferior $(p=0,050469)$.

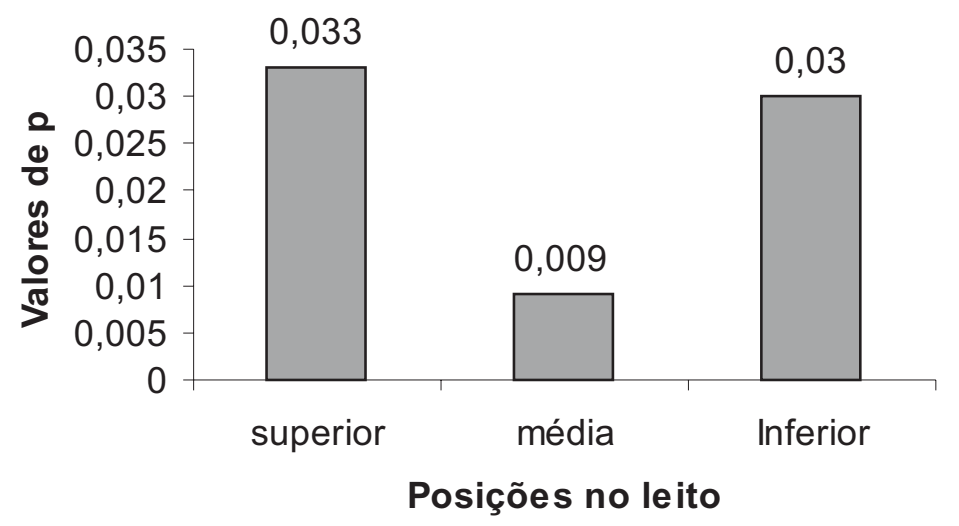

Figura 1 - Redução do número de colônias de Staphylococcus aureus, de acordo com a posição no leito, após a limpeza e desinfecção nas amostras obtidas em meio de cultivo ágar sangue. Teste Wilcoxon; $p<0,05$.

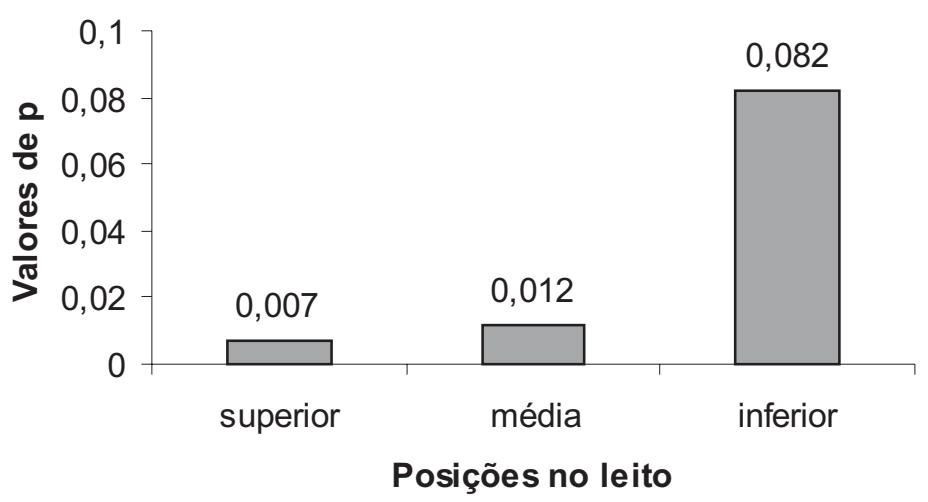

Figura 2 - Redução do número de colônias de Staphylococcus aureus, de acordo com a posição no leito, após limpeza e desinfecção nas amostras obtidas em meio de cultivo ágar manitol. Teste Wilcoxon; $p<0,05$.

\section{DISCUSSÃO}

Pode-se notar que as colônias de $S$. aureus, provenientes de meio ágar manitol, aumentaram progressivamente da posição superior para posição inferior, após a limpeza e desinfecção. Além disto, em posição inferior, evidenciou-se uma redução não significativa $p>0,05$. O meio cultivo manitol, por si só, já é seletivo para $S$. aureus. O que corrobora tais resultados é o padrão semelhante encontrado nas provas de coagulase, aumento progressivo do número de provas positivas de regiões superior para inferior culminando com redução não significativa em posição inferior $p>0,05$. Associando o fato do meio de cultivo 
manitol ser seletivo para $S$. aureus e a prova de coagulase ser específica para identificação presuntiva dessa espécie bacteriana, inferiu-se que após a desinfecção e limpeza, as colônias de $S$. aureus, quando presentes, estavam sendo deslocadas para posições inferiores dos colchões. Aparentemente, os colchões estavam sempre sendo limpos da posição superior para inferior, independente do paciente que tivera ocupado o leito e sua doença.

Era de se esperar que o comportamento do número de provas de coagulase positivas e do número de colônias de $S$. aureus, obtidas de meio ágar sangue, fossem semelhantes ao obtido do ágar manitol já que, em cada coleta, a amostra para ambos os meios de cultivo era a mesma. Além disto, por ser um meio rico, o ágar manitol facilita ainda mais o crescimento dessa bactéria. $O$ que pode explicar essa divergência de resultados é o fato de ter havido crescimento de outros microorganismos em meio ágar sangue, tais como outros cocos gram positivos, fungos e bacilos gram negativos, em quantidade suficiente para interferir no crescimento de $S$. aureus. Além disto, devido ao grande número de microrganismos, a triagem realizada pela identificação morfológica por observação microscópica pode ter sido prejudicada. Com base nestes dados, podemos inferir que o meio de cultivo ágar sangue não se mostrou eficiente para os propósitos preconizados por esse trabalho.

É importante salientar que os resultados obtidos do meio ágar manitol, e confirmados pelas provas de coagulase, refletem a necessidade de uma reavaliação criteriosa nos procedimentos de limpeza e desinfecção atualmente empregados nos colchões. Embora o objetivo deste trabalho tenha sido somente relacionado ao $S$. aureus, outros microrganismos tão patogênicos quanto essa bactéria podem estar apresentando o mesmo padrão de comportamento já descrito, por outros autores. Os autores concluem ser imprescindível que o processo de desinfecção, nos leitos hospitalares, deva ser realizado de acordo com a necessidade e não segundo critérios prédeterminados.

\section{REFERÊNCIAS BIBLIOGRÁFICAS}

1. Bryan LE. General mechanisms of resistence to antibiots. Journal of Antimicrobiology Chemotherapy 22:1-15, 1988.

2. Cohen ML, Wong ES, Falkows $S$. Common R plasmidis in Staphylococcus aureu and Staphylococcus epidermidis during nosocomial Staphylococcus aureus outbreak. Antimicrobiology Agents Chemotherapy 21:210-215, 1982.

3. Hwang MH, Pyo YJ, Mun HM, Pai CH. Clonal Spread of Staphylococcus aureus Heterogeneously Resistance to Vancomycin in a University Hospital in Korea. Journal of Clinical Microbiology 40: 1376-1380, 2002.

4. Levy CE, Costa JC, Lama J, Furlan MLS, Toloy RC, Pasti MJ, Takeda E. Papel epidemiológico das mãos nas infecções hospitalares. Revista da Sociedade Brasileira de Medicina Tropical 21: 89, 1988.

5. Lytsky BY. Sterelity assurance in hospital. Who's responsibility? Association of Operating Room Nurses Journal 27:200-201, 1978.
6. Marples DG. The normal flora of human skin. Journal of Dermatology 81:15-17, 1969.

7. Maxwell JG, Ford CR, Peterson DE, Mitchell CR. Long term study of nasal staphylococci among hospital personal. American Journal of Surgery 116: 849-854, 1969.

8. Monteiro J. As infecções nosocomiais. Acta Medica 6:135-140, 1993.

9. Steere AC, Mallison GF. Controle de infecções no hospital. Editora da Universidade de São Paulo, São Paulo, 1989.

10. Washington II, Lennette EH, Balows A, Hausler WJ, Shadomy HJ. A susceptibility test: agar diluition. Manual of Clinical Microbiology, $4^{\text {th }}$ edition, American Society for Microbiology, Washington, 1985.

11. Wenzel RP, Nettleman MD, Jones NR, Pfaller MA. A methicillinresistence Staphylococcus aureus: Implications for the 1990s and effective control messures. The American Journal of Medicine 91:221-227, 1991. 